\title{
Trabajadores de los hidrocarburos en la Patagonia Austral. La conflictividad del trabajo en YPF (2003-2019)
}

\section{Oil workers in Southern Patagonia. The conflict of work at YPF (2003-2019)}

\author{
Agustina Súnico \\ agustinasunico@gmail.com \\ Instituto de Investigaciones Gino Germani - Facultad de Ciencias Sociales \\ Universidad de Buenos Aires \\ Uriburu 950 Piso 6 - Ciudad Autónoma de Buenos Aires - Argentina
}

Recibido: 27/03/2020. Aceptado: 17/11/2020

\begin{abstract}
RESUMEN
En el presente artículo nos proponemos dar cuenta de la conflictividad protagonizada por los trabajadores en relación a la empresa hidrocarburífera YPF, en el Golfo San Jorge, durante los años 2003-2019. Abordamos la conflictividad en relación con los cambios ocurridos en la empresa y en la política sectorial durante el período abordado. En este sentido, contemplamos distintas etapas de YPF (privada, bajo control mayoritario estatal y los cambios de gestión en ésta última etapa de la empresa).

La estrategia metodológica radica en el análisis de un catálogo de episodios de acciones colectivas contenciosas, de elaboración propia, con base en la prensa. Hacemos hincapié en los actores protagonistas de la acción, las demandas esgrimidas y las formas de acción.
\end{abstract}

Palabras clave: YPF; Petroleros; Conflicto Laboral; Estado.

\begin{abstract}
This paper deals with the conflict of workers in relationship to YPF oil company, during the 2003-2019, in the Golfo San Jorge basin. We address the conflict in relation to changes in the company and sectoral policy during that period. In this sense, we contemplate different stages of YPF (private, under majority state control and management changes in this last stage of the company). The methodological strategy lies in the analysis of a catalogue of episodes of contentious collective actions, of own elaboration, based on the press. We emphasize the actors, demands and forms of action.
\end{abstract}

Keywords: YPF; Oil Workers; Labor Conflict; State. 


\section{INTRODUCCIÓN}

En el presente artículo nos proponemos abordar la conflictividad protagonizada por los trabajadores en relación a la empresa hidrocarburífera YPF, en la cuenca del Golfo San Jorge (CGSJ), durante los años 2003-2019.

A lo largo de los años, la empresa ha sido objeto de distintas transformaciones en cuanto a sus características y propiedad. Se creó como Yacimientos Petrolíferos Fiscales, Sociedad del Estado, en el año 1922. En la década de los noventa, durante el proceso de desregulación del sector hidrocarburífero, encarado por el gobierno nacional de dichos años, la empresa fue privatizada, conformándose como Sociedad Anónima. Sus acciones fueron progresivamente vendidas, hasta que finalmente la compañía Repsol ${ }^{1}$ alcanzó la mayoría accionaria, convirtiéndose en su principal controlante. A partir de entonces, se llevó adelante una estrategia que priorizó la valorización en el corto plazo del recurso, en pos de aumentar el margen de ganancias (Serrani, 2013). Con el tiempo, este accionar, tuvo consecuencias regresivas denotadas en los principales indicadores de la empresa, especialmente en términos de producción y reservas (Serrani, 2013, Barrera, 2013). El comportamiento productivo de YPF, sumado a la conducta similar del resto de las compañías del sector (Barrera, 2012), coadyuvó hacia el año 2011, a la necesidad de importar combustibles, en un contexto de crecimiento de la demanda energética, debido a la recuperación económica producida a partir de 2003 (Sabbatella, 2012). En este marco, en el año 2012, se dictaminó la expropiación del paquete accionario mayoritario de YPF. El objetivo que guío la re-estatización parcial y que se plasmó en la Ley $\mathrm{N}^{\circ} 26.741$ de Soberanía Hidrocarburífera, radicó en alcanzar el autoabastecimiento energético, para lo cual, el rol de YPF sería central. En consonancia, se produjo un redireccionamiento de los objetivos productivos de la empresa, en pos de una mayor inversión en la misma, que redundó en una mejora de los indicadores (Barrera, et al., 2015).

Posteriormente, a partir del año 2016, la nueva administración nacional (Mauricio Macri de la alianza Cambiemos entre 2016-2019), propugnó la desregulación del sector y la disminución del rol central de YPF como herramienta de la política pública (Serrani, et al., 2017) En dicho contexto, se produjeron cambios en la estrategia comercial de la empresa y disminuyó su actividad, con consecuencias regresivas en materia de empleo (Landriscini, 2017).

Ante estas transformaciones, nos preguntamos ¿Cómo se desarrolló la conflictividad de los trabajadores vinculada a la empresa? ¿Sobre qué ejes se estructuró la conflictividad de los trabajadores en la etapa privada, la nueva etapa bajo control mayoritario estatal y las distintas gestiones? y ¿Qué cambios y continuidades se produjeron en las demandas y las formas de acción de los trabajadores? Esta dimensión es de particular importancia, ya que en torno a YPF se canalizaron históricamente una multiplicidad de confrontaciones en relación al trabajo (Svampa, 2002, Landriscini, 2017).

La cuenca del Golfo San Jorge se configura como un espacio central para observar las transformaciones del período, respecto a la actividad hidrocarburífera, a la empresa en particular y la dinámica del conflicto en relación a la misma. La misma abarca $200.000 \mathrm{~km} 2$. Cubre el sur de la provincia de Chubut y Norte de Santa Cruz, desde la Cordillera de los Andes hasta la plataforma continental. La cuenca es una de las más importantes del país en cuanto a sus niveles de producción, aportando el $48 \%$ de petróleo a nivel nacional. A su vez, YPF, es una las productoras con mayor peso en dicha región, extrayendo el $40 \%$ de su petróleo de la misma. En adición, es la principal empresa productora de hidrocarburos de la provincia de Santa Cruz (59\% para la producción de petróleo) y la segunda para el caso de Chubut (22\% para el petróleo, detrás de PAE con el 61\%) (Ministerio de Hacienda, 2017,

\footnotetext{
${ }^{1}$ Repsol S.A., es una compañía de origen español, que en el año 1999 adquirió el 97,46\% de las acciones de
} YPF. 
2018b). Para las provincias que integran la cuenca, las actividades de producción primaria y extractivas son un elemento central de sus entramados productivos (Schinelli, et al., 2019). Entre ellas, la actividad hidrocarburífera es de gran importancia para sus economías, dada la relevancia de las regalías petroleras en los presupuestos provinciales (Villarroel, Schinelli y Vacca, 2018). Las principales localidades que se ubican en la cuenca- Comodoro Rivadavia, Caleta Olivia, Pico Truncado, Cañadon Seco y Las Heras- presentan un perfil sectorial donde predomina una dinámica de empleo marcada por la actividad hidrocarburífera (Prado y Robledo, 2015a, 2015b; Schinelli, et al., 2019). En este sentido, priman los conflictos ligados a problemáticas vinculadas al trabajo petrolero (Vega et al., 2012). Por último, la relevancia de la compañía en estudio reside también en su rol, en términos materiales, sociales y simbólicos, en el desarrollo histórico de dichas localidades (Salvia,1999; Acconcia y Álvarez, 2008; Palermo, 2012, 2013; Prado y Robledo, 2015b).

Ante lo mencionado, en el presente artículo nos proponemos abordar las transformaciones acaecidas en la empresa y en el sector, haciendo hincapié particularmente en lo ocurrido en el Golfo San Jorge. A su vez, caracterizaremos la evolución de la conflictividad de los trabajadores vinculada a la empresa, en la cuenca, durante el período 2003-2019. Buscamos dar cuenta de las diferencias y similitudes en las características de la conflictividad entre las etapas privada y bajo control estatal y las gestiones de esta última.

Con este fin, el artículo se estructura a partir de una serie de apartados. En los dos primeros detallamos el marco teórico y la estrategia metodológica aplicada. En el siguiente, presentamos los principales resultados y el análisis realizado. Procedemos a un recorrido sucinto de las principales políticas públicas hacia el sector y, especialmente, focalizamos en los procesos ocurridos en la empresa a nivel nacional y en la región en estudio. Luego, describimos la evolución de la conflictividad de los trabajadores vinculada con YPF durante el período. Hacemos hincapié en los actores protagonistas de los episodios contenciosos, las demandas esgrimidas y las formas de acción empleadas. Por último, finalizamos con unas breves reflexiones. $^{2}$

\section{MARCO TEÓRICO}

Nuestro marco teórico se concibe a partir de la articulación de conceptos de distintas perspectivas con el fin de abordar diversos elementos que en su interacción influyen en la conflictividad: los cambios ocurridos en la forma socio-productiva de la empresa en estudio y los procesos político- institucionales. Así, retomamos la propuesta teórica de corrientes neomarxistas, a partir de Erik Olin Wright $(2010,2013)$ y los desarrollos de los teóricos de los procesos políticos en el campo de la acción colectiva, con Charles Tilly $(2000,2008)$ y Sidney Tarrow $(1999,2008)$.

Partimos de la propuesta teórico-analítica de Wright $(2010,2013)$ respecto al estudio de las relaciones entre una forma productiva y los tipos de conflictos que en ella se configuran. Para el autor, de acuerdo a cómo se organiza la producción de un bien se establecen ciertas potencialidades que hacen más favorable la emergencia y el desarrollo de determinados tipos de conflictividad. En este sentido, las características de una forma productiva son un elemento fundamental para entender la conflictividad potencial que en torno a ella puede configurarse. Ésta refiere al modo en el cual se organizan las relaciones de poder por las cuales se distribuyen, controlan y utilizan los recursos económicos. El autor, distingue al capitalismo, al estatismo y al socialismo, como estructuras económicas puras, diferenciadas por el tipo de poder (económico-estatal-social) y la propiedad (privada-estatal-social), mientras que en las sociedades reales existen una diversidad de casos mixtos a partir de los cuales se configuran

\footnotetext{
${ }^{2}$ Los avances del presente artículo forman parte de la tesis de maestría en elaboración (FSOC-UBA). La investigación cuenta con el apoyo económico de una la beca de maestría UBACyT.
} 
patrones complejos de relaciones de poder. Estos dan lugar a formas híbridas o interpenetradas, cuya estructura está dada por el modo particular en el que se ordenen las distintas lógicas, tales como capitalismo-estatal.

En el caso de YPF, como mencionamos, la compañía deja de detentar un carácter privado, al ser re-estatizada parcialmente en el año 2012, a partir de lo cual adquiere un carácter híbrido de tipo capitalista-estatal. En estos casos, como plantea Wright, la combinación de diferentes lógicas implica dinámicas contradictorias, lo que hace que las formas interpenetradas sean inestables. Esta situación lleva a que alguna de las formas de poder tienda a prevalecer sobre las otras. Por lo tanto, lo fundamental resulta en identificar cuál es la lógica de poder dominante en cada momento (Pérez, 2015).

Con el objetivo de indagar en los procesos políticos e institucionales, retomamos también a autores clásicos de la acción colectiva: Charles Tilly (2000; 2008) y Sidney Tarrow (1999, 2008). Los autores analizan la conflictividad en relación con las características de los regímenes políticos socialmente contextualizados. Los procesos y transformaciones que ocurren a nivel macro-social ejercen una gran influencia en el surgimiento, la extensión y la forma que adoptan las confrontaciones. Esto es así debido a que, las variaciones en el sistema político e institucional conllevan cambios en la estructura de oportunidades políticas en relación con las condiciones que posibilitan o desincentivan la acción colectiva. Estos cambios se pueden relacionar con una serie de dimensiones, el grado de apertura o cierre del sistema político, la posibilidad de quienes se movilizan para conseguir el apoyo de aliados, la capacidad y la tendencia estatal a reprimir o permitir el desarrollo de la protesta y las divisiones entre los grupos de las elites que dan lugar a resquicios para la acción, entre otras (Tarrow; 1999; Tilly 2008). Los cambios en las condiciones políticas generan oportunidades para que grupos que carecían de influencia o acceso formal a las esferas de poder logren hacerlo. En conclusión, Tarrow y Tilly nos dan la pauta para indagar en el momento en el que surgen las confrontaciones, al contemplar los cambios en el sistema político-institucional, que se configuran como oportunidades a partir de las cuales emergen las acciones colectivas.

\section{ESTRATEGIA METODOLÓGICA}

\subsection{Precisiones metodológicas}

En cuanto a la estrategia metodológica, trabajamos con una base de datos de elaboración propia en la que se registraron todos los episodios contenciosos, referidos a la conflictividad de los trabajadores, vinculados con YPF, en las cuencas hidrocarburíferas Neuquina y del Golfo San Jorge, durante los años 2003- 6/2019, publicados en la prensa (Base YPF-IIGG). En este caso, pondremos el foco en la Cuenca del Golfo San Jorge. Nos centramos en el sector upstream de la actividad, que comprende la exploración, perforación y explotación, al ser actividades centrales de la empresa y las regiones en estudio, que concentran una gran cantidad de trabajadores.

Es preciso en este punto realizar una serie de apreciaciones en torno al uso de la prensa como fuente de registro para la elaboración de catálogos de eventos de conflicto. Por un lado, ésta presenta una serie de ventajas respecto a su accesibilidad, periodicidad y presentación de datos fiables. A través de la prensa, es posible obtener información sobre lugares, fechas, actores, formas de acción y demandas de los conflictos. Por otro lado, es necesario también tener presente sus riesgos (Río, 2008; Franzosi, 2017). Los medios son un actor más en los fenómenos sociales estudiados, que crean sentidos e influyen en la forma en la que son tratados los hechos. En consecuencia, la selección y presentación de los eventos se encuentra sesgada por una estrategia y política editorial específica. De modo que, ciertos hechos suelen ser incluidos más que otros, lo que implica un riesgo en cuanto a la sub-representación o sobre-representación de ciertos eventos. Siendo este sesgo no sistemático en el tiempo. No 
obstante, esto se ve matizado debido a que el margen de manipulación es limitado, dadas las exigencias de legitimidad y credibilidad de las que todo medio debe disponer en su lógica de producción de la noticia. Esto se vincula con criterios de fiabilidad que conllevan el cumplimiento de estándares de objetividad y relevancia (Schuster et. al., 2006).

En particular, la elaboración de catálogos de eventos de conflictividad con base a la prensa es un recurso habitual en la investigación social. Estos permiten reconstruir series a largo plazo, al reunir episodios dispersos en el espacio y en el tiempo. Así también, facilitan observar variaciones en la incidencia de un tipo particular de acción colectiva a lo largo de un período. De esta manera, es posible realizar cronologías y caracterizaciones generales del conflicto. En el ámbito local e internacional pueden identificarse diversos antecedentes que emplean esta metodología (Marín, 2007; Tilly, 2008; Silver, 2005; Schuster et. al., 2006).

Teniendo en cuenta los aspectos mencionados, para la elaboración del catálogo empleado en el presente artículo, se buscó minimizar los riesgos, recurriendo a diversos medios periodísticos, tanto de nivel nacional como local. Esto permitió disminuir el subregistro y complementar líneas editoriales. Se trabajó con los diarios La Nación, Río Negro y Tiempo Sur.

Los episodios contemplados en el catálogo elaborado son considerados en virtud de su unidad de sentido, dada por la existencia de un actor, meta o demanda, forma de acción y destinatario en común ${ }^{3}$, sincronización temporal y convergencia en el tiempo. Se alcanzó un total de 164 episodios contenciosos. En al análisis cuantitativo trabajamos con variables de respuesta múltiple. En un mismo episodio pueden ser empleadas varias formas de acción, tales como la huelga, la concentración, el corte de rutas, etc. Así también sucede con los actores protagonistas, ya que, por ejemplo, distintos sindicatos pueden protagonizar un mismo episodio. Lo mismo ocurre con las demandas que los actores esgrimen (incrementos salariales y mejoras en las condiciones laborales, por ejemplo). Para el procesamiento y análisis de estas variables se calcularon los porcentajes sobre el total de los casos y no sobre el total de las respuestas, para dar cuenta de este modo de su participación en relación a la totalidad de los eventos de conflictividad. Es por esto que, como se verá en el desarrollo del artículo, la suma de los porcentajes supera el $100 \%$.

Para la reconstrucción de los cambios en el sector y en YPF, nos basamos en investigaciones en la temática, informes y estadísticas oficiales e informes realizados por la empresa.

Hechas estas distinciones, en el próximo apartado realizamos un recorrido sucinto de las transformaciones en la política sectorial y en la empresa en estudio. Luego, abordamos la evolución de la conflictividad durante el período.

\section{RESULTADOS- ANÁLISIS}

4.1 Las políticas públicas hacia el sector hidrocarburífero y los cambios en YPF durante los años 2003-2019

\subsubsection{La estrategia de Repsol en YPF y las tensiones en la posconvertibilidad}

Durante la década de los noventa, en el marco de una serie de transformaciones estructurales, se avanzó en la desregulación del sector de los hidrocarburos y la privatización de la empresa estatal Yacimientos Petrolíferos Fiscales S.E. (Salvia, 1999, Mansilla, 2007, Barrera, 2011, 2012, 2013; Sabbatella, 2012; Serrani, 2013). A partir de entonces, la estrategia productiva y comercial desplegada por las principales compañías y particularmente por YPF, consistió en la maximización de utilidades en el corto plazo a partir de la reducción de las inversiones de riesgo involucradas en la etapa de exploración y la sobreexplotación de los yacimientos

\footnotetext{
${ }^{3}$ En todos los episodios YPF es interpelada como objeto de las demandas.
} 
(Barrera, 2012, 2013). Esta lógica tuvo como consecuencia un descenso sostenido de la producción hidrocarburífera e impactó asimismo en los niveles de reservas (Mansilla, 2007; Sabbatella 2012, Barrera, 2012, 2013; Serrani, 2013). A partir del año 2003, la reactivación de la economía conllevó un marcado crecimiento de la demanda energética que colisionó con la lógica comercial de las principales compañías del segmento (Sabbatella, 2012, Porta, Santarcángelo y Schteingart, 2017, Kulfas, 2019). Ante este panorama, el gobierno nacional aumentó la presencia estatal y los controles sobre el sector. ${ }^{4}$ Se aplicaron políticas regulatorias de manejo interno de precios y las retenciones se convirtieron en uno de los principales instrumentos de la política hacia el sector (Sabbatella, 2012; Serrani, 2013). Al mismo tiempo, se implementaron programas de incentivo que buscaron impulsar el aumento en las inversiones y la producción (Sabbatella, 2012). Se estableció un marco de beneficios fiscales, como, por ejemplo, la "Ley 26.154 de Regímenes Promocionales para la Exploración y Explotación de Hidrocarburos" (2006). En el año 2008, se lanzaron los programas Gas Plus, Petróleo Plus y Refinación Plus, que concedían beneficios en los precios y fiscales a la producción excedente. Se sostuvo el precio obtenido por las productoras y distribuidoras de gas natural a partir del otorgamiento de subsidios al consumo. ${ }^{5}$ Sin embargo, se mantuvieron marcos normativos que otorgaron libertad a las empresas para disponer del destino de la producción y las ganancias (Barrera, 2012, 2013). En este contexto, las empresas continuaron con la estrategia cortoplacista y se mantuvo la tendencia declinante en la producción y las reservas.

En el caso de la empresa que nos convoca, la explotación se centró en los yacimientos ya productivos, en su mayoría descubiertos por la YPF estatal, con el objeto de obtener saldos exportables que redundaran en crecientes ganancias. A su vez, éstas eran destinadas al financiamiento de inversiones en otros lugares del mundo, considerados estratégicos por la compañía controlante (Repsol), así como también transferidas, en la distribución de dividendos, a los accionistas (Serrani, 2013). Un intento por parte del gobierno nacional para revertir este comportamiento consistió, en el año 2007, en promover la apertura de YPF a capitales argentinos impulsando el ingreso del Grupo Petersen. Se estimó que el diálogo sería más favorable con empresarios nacionales, lo que permitiría incidir en las decisiones de la empresa. Sin embargo, su ingreso potenció la redistribución y fuga de utilidades al realizarse la entrada del Grupo Petersen, mediante un crédito que obtenía de la empresa (Repsol) de la que pasaba a ser accionista (Serrani, 2013).

Si observamos los indicadores de la empresa en estudio, entre el año 2003 y 2011, a nivel nacional, la producción de petróleo de YPF presentó una caída del 41\%. La misma tendencia se presentó en el caso del gas, con una baja del 37\% (Secretaría de Energía de la Nación, 2019). Si distinguimos la participación de la empresa en el total de la producción, identificamos asimismo una pérdida sostenida en su proporción. Paro el caso del petróleo, en

\footnotetext{
${ }^{4}$ Respecto al rol del Estado Nacional y de las administraciones provinciales, es importante destacar la sanción de la Ley Federal de Hidrocarburos $\mathrm{N}^{\circ}$ 26.197, en el año 2006, también denominada como "Ley Corta". Ésta transfirió los permisos, concesiones o contratos aprobados por el Estado Nacional a los Estados Provinciales, a la vez que los convirtió en autoridad de aplicación y dictaminó el cobro directo de las regalías. La Ley profundizó el dominio provincial sobre el recurso, iniciado con la Ley $\mathrm{N}^{\circ} 24.145$ de Federalización de Hidrocarburos, sancionada en el año 1992. La misma transfirió el dominio público de los yacimientos del Estado Nacional a las Provincias, excluyendo ciertas áreas. Luego, en el año 1994, mediante la reforma constitucional se estableció en la misma que corresponde a las provincias el dominio originario sobre los recursos naturales existentes en su territorio. De esta manera, la "Ley Corta" concluyó un proceso de provincialización iniciado en la década del noventa y habilitó a las provincias para negociar las condiciones de los contratos de concesión y fijar condiciones al desarrollo de la actividad de las empresas en su territorio (Prado y Robledo, 2015). A pesar de estas modificaciones, el Gobierno Nacional se reserva el diseño de las políticas energéticas en el nivel federal.

${ }^{5}$ Esta operación se realizaba mediante el establecimiento de tarifas diferenciales, es decir inferiores a las tarifas plenas, en las que el Estado asumía la diferencia entre el precio cobrado a los consumidores y el precio en boca de pozo.
} 
el año 2003, YPF representaba el 45\% del total, mientras que para el año 2011, el porcentaje era del 34\%. En el caso del gas, para los mismos años pasa del $33 \%$ al $23 \%$. Al focalizar en la CGSJ observamos la misma tendencia, con caídas que superan los porcentajes del total de lo producido en la cuenca, lo que nos da la pauta de la magnitud de la disminución de la actividad de la empresa. Para el caso del petróleo se observa un descenso del 34\% (el total de la cuenca presenta una caída del 9\%). En el caso del gas, YPF registró una caída del 37\% (en la cuenca la caída es del 10\%). Misma propensión a la baja se hace presente en la participación de YPF en el total de la producción de la cuenca en estudio. En materia de petróleo, en el año 2003, YPF representaba el 43\%, mientras que, en el año 2011, el porcentaje desciende a 31\%. En el caso del gas, pasa de representar el 52\% del total al 39\%, en el mismo período.

Si bien, en estos años se registra un descenso continuo de la extracción, la actividad de la empresa y del sector en general, impulsada por los altos precios internacionales, se mantuvo relativamente constante hasta el año 2008, sin registrarse momentos críticos de caída abrupta ("El crudo no", 31 de julio de 2004; Buci, Herrera y Jones, 2016). Hacia fines de dicho año y especialmente en el año 2009, en el marco de un contexto de caída en el precio internacional de los hidrocarburos, ${ }^{6}$ se produjo una situación crítica para el sector que afectó fuertemente la cuenca en estudio (Buci, Herrera y Jones, 2016). En materia de empleo, los trabajadores se vieron afectados particularmente en dicho momento, cuando las empresas, incluyendo a YPF, disminuyeron inversiones y llevaron adelante un ajuste que redundó en la detención de equipos de perforación y despidos ("La cámara petrolera", 27 de febrero de 2009; "Riesco advirtió sobre", 27 de marzo de 2009). Así, ante un contexto en el que disminuyeron las condiciones de valorización del recurso, la empresa recurrió a la baja de equipos y despidos ("Neuquén convoca a YPF", 15 de febrero de 2009).

La sostenida regresión en los volúmenes de producción en el país durante estos años, coadyuvó a que se debieran asumir cuantiosas compras externas de combustibles. Entre los años 2003 y 2011 la extracción de crudo se redujo en un $22 \%$ mientras que la de gas en un $11 \%$. Esto produjo que, hacia el año 2011, se generara un déficit en la balanza comercial energética (Barrera, 2012). Dada la importancia del peso de YPF en la cadena hidrocarburífera, esta situación derivó en un enfrentamiento entre el gobierno nacional y la empresa Repsol, principal accionaria de la empresa (Koziner y Zunino, 2013; Prado y Robledo, 2015b). En este contexto se produjo un giro sustancial en la política sectorial que propició un cambio integral de la estructura regulatoria y afectó especialmente a YPF, como veremos a continuación.

\subsubsection{El retorno del control estatal en la empresa y la regulación integral del sector}

El año 2012 marcó el inicio de una nueva etapa en el desarrollo de la política sectorial y particularmente para la empresa en estudio. La Ley $\mathrm{N}^{\circ} 26.741$ de Soberanía Hidrocarburífera y su Decreto Reglamentario $N^{\circ} 1277 / 12$ determinó el regreso de la presencia del Estado en el sector por medio de la re-estatización de YPF y de la regulación integral de la actividad (Sabbatella, 2012; Prado y Robledo, 2015b). La Ley estableció la expropiación del paquete accionario mayoritario de YPF $(51 \%)$. La compañía adquirió así un carácter híbrido capitalista-estatal, en términos de Wright (2013). Si profundizamos en los atributos que adquirió este proceso identificamos que la re-estatización se dio de manera parcial. El Estado asumió el control mayoritario de la compañía, en combinación con acciones bajo propiedad de capitales privados. Asimismo, la compañía mantuvo su figura de Sociedad Anónima y

\footnotetext{
${ }^{6}$ El precio internacional de los hidrocarburos presentó una tendencia alcista hasta que descendió abruptamente entre 2008 y 2009, para luego iniciar nuevamente un ciclo alcista, especialmente entre 2011 y 2014, año en que nuevamente cae la cotización (Ministerio de Hacienda, 2016). A pesar de esto, los planes de estímulo brindaban la posibilidad de obtener mayores ingresos.
} 
prosiguió operando en las bolsas locales y de Nueva York. A la vez, se contempló la posibilidad de acuerdos de operación conjunta con capitales internacionales. Por otro lado, no se produjo una re-estructuración de la compañía hacia su configuración en sus inicios estatales. Es decir, cuando la empresa abarcaba todas las actividades involucradas en el proceso productivo mediante trabajadores bajo contrato directo. No obstante, se produjeron una serie de rupturas con la etapa previa, que es importante tener en cuenta. Como veremos a continuación, se produjo un giro en su lógica productiva que redundó en cambios en sus indicadores.

En conjunto con la implementación de medidas y programas para apuntalar el funcionamiento de la actividad, desde el Estado se impulsó la utilización de YPF como una herramienta estratégica para estimular las inversiones y la producción. (Landriscini, 2015, 2017; Porta, Santarcángelo y Schteingart, 2017; Kulfas, 2019). Así, por un lado, se conformó un nuevo entramado regulatorio que le otorgó al Estado mayor control sobre el sector. ${ }^{7}$ Por el otro, se implementaron políticas y medidas específicas que buscaron actuar como un sostén, estimulando inversiones en el ámbito local (Sabbatella, 2012). Se continuó con programas que otorgaban beneficios tanto fiscales como en los precios, a aquellas compañías con producción excedente de gas y petróleo. Una de las principales medidas fue el establecimiento de un precio interno diferencial, para sostener los niveles de actividad, ante la tendencia a la baja del precio internacional de los hidrocarburos (Barrera, et al., 2015).

En cuanto a la empresa en estudio, se produjo un giro en su estrategia productiva. Se revirtió la dinámica de desinversión y reparto de dividendos entre los accionistas llevada adelante por Repsol, lo que se tradujo en un incremento de las inversiones en la empresa (Barrera et al., 2015). El objetivo de las mismas radicó en recuperar el segmento de exploración y estimular la producción (Landriscini, 2015, 2017). Como sugieren Barrea et al. (2015), esto es posible de observar en las cantidades de pozos terminados de exploración y explotación de la empresa. A nivel nacional, se incrementó notoriamente la exploración. Se pasó de 11 perforaciones en el año 2011 a 37 en el año 2015. Entre el año 2012 y 2015 se registró una expansión del 147\%. En cuanto a los pozos de explotación, en el año 2011, YPF registró un total de 447, mientras que, en el año 2015, el número ascendió a los 719. Entre el año 2012 y 2015 se produjo un alza del 87\% en las perforaciones. En la Cuenca del Golfo San Jorge el cambio fue notorio. En el año 2011 se registraban 0 pozos de exploración, mientras que en el año 2015 se alcanzaron 9 pozos. Entre ellos, 6 corresponden al norte de Santa Cruz y 3 a Chubut. Para el caso de los pozos de explotación, también se dio una tendencia ascendente, con el paso de 314 pozos en el año 2011 a 325 en el año 2015.

Este cambio en la estrategia productiva se tradujo en una reversión de la tendencia descendente en la producción de la empresa. A nivel país, entre el año 2012 y 2015, su producción de petróleo aumentó en un $20 \%$, mientras que la de gas lo hizo en un $38 \%$. En la cuenca en análisis, también podemos observar una mejora en sus indicadores. En el caso del petróleo la compañía evidenció un crecimiento de $10 \%$ en la extracción y para el gas un aumento del 39\%, (aunque es marginal en esta zona su producción). Los valores superan el aumento a nivel total en la cuenca. En ésta se registró un aumento del $1 \%$ y en el gas del $10 \% .^{8}$

\footnotetext{
${ }^{7}$ A partir de la Ley y su decreto reglamentario se crearon distintas instituciones que le otorgaron mayor capacidad de control al Estado sobre la actividad, especialmente sobre los planes de inversiones de las empresas. Ejemplo de las mismas son la "Comisión de Planificación y Coordinación estratégica del Plan Nacional de Inversiones Hidrocarburíferas" y el "Registro Nacional de Inversiones Hidrocarburíferas".

${ }^{8}$ Los yacimientos de la Cuenca del Golfo San Jorge se encuentran en estado de maduración avanzado por lo que las inversiones realizadas en materia de explotación, especialmente de carácter secundario, son de suma relevancia para mantener los niveles de producción (Ministerio de Hacienda, 2018a).
} 
Como señalan distintos autores (Barrera et al., 2015; Barneix, 2016; Porta Santarcángelo y Schteingart, 2017; Kulfas, 2019), el giro en la dinámica productiva de la empresa no fue acompañado en la misma medida por las restantes compañías del segmento. Al observar la participación de YPF en el total de la producción del país, se evidencia que los mayores esfuerzos extractivos corresponden a dicha compañía. En cuanto a la producción de petróleo, la empresa pasó de representar el 34\% en el año 2011 al 43\% en el año 2015. Respecto al gas, YPF pasó de representar el 23\% de la producción total en el año 2011, al 33\% en el 2015. Asimismo, si observamos la participación de la compañía en el total de la producción de la Cuenca del Golfo San Jorge, observamos también una tendencia creciente. En el año 2011 representaba el 31\% del total. Este porcentaje asciende al 35\% al final del año 2012 y al 39\% en el año 2015. Para el caso del gas, en el año 2011, representaba el 39\%, mientras que para el año 2015 el porcentaje asciende a $52 \%$.

Por último, cabe destacar que el aumento en la actividad de YPF también estimuló la creación de puestos laborales (Barrera et al., 2015; Landriscini, 2017). Se produjo un incremento en el empleo de la empresa, tanto de manera directa como a través de sus contratistas. Contando el total (directo, empresas controladas y contratistas), se pasó de 45.812 empleados, en el año 2011, a 71.641 en el año 2015 (aumento del 56\%). Particularmente, los trabajadores de las contratistas aumentaron de 29.746 a 49.627 para el mismo período (aumento de un 67\%) (YPF, 2015). Otro aspecto que se destaca es un cambio en la relación de YPF con las empresas contratistas. Se desarrollaron programas específicos para promover el desarrollo de proveedores locales, tales como el programa Sustenta (Barrera, et al., 2015).

La combinación de políticas y medidas de fomento a la actividad junto a la iniciativa de YPF dieron como resultado un quiebre en el proceso de descenso acelerado de la producción. Para la producción total del país, en el caso del petróleo, si bien no se revirtió la caída (entre 2012 y 2015 se registra una caída del 3\%), la producción se estabilizó luego del año 2013. Mientras que, para el caso del gas, luego de una disminución de la extracción en el año 2013, comenzó una recuperación de la producción (entre dicho año y el año 2015 se registró un aumento del $3 \%$ ). No obstante, es importante destacar que, hacia fines del año 2015 se evidenciaron límites en este proceso de recuperación. Se produjo una baja en la actividad, que se tradujo en la paralización de equipos tanto a nivel sectorial como en YPF ("Buscan frenar despidos" 21 de mayo de 2015; "El 30\% de", 19 de diciembre de 2015).

El recambio gubernamental a nivel nacional conllevará a transformaciones tanto para el sector como para la empresa, como veremos en el siguiente apartado.

\subsubsection{Hacia la desregulación sectorial y la separación de la empresa de la política pública}

En diciembre de 2015 asumió el gobierno del Estado una fuerza política con una orientación contrastante a la del gobierno anterior. En cuanto al sector hidrocarburífero, se postuló que era necesario avanzar en la desregulación sectorial y en la reducción de subsidios. Se realizó una revisión del entramado regulatorio y de funcionamiento de la actividad (Landriscini, 2017; Serrani et al., 2017). Se disolvieron instituciones, disminuyendo las facultades de control. ${ }^{9}$ En cuanto al esquema de precios, se buscó alcanzar una unificación con el precio internacional. Se eliminaron las retenciones a las exportaciones de hidrocarburos ${ }^{10} \mathrm{y}$ se extendieron los plazos de ingreso de divisas al sistema financiero. En 2017, se lanzó el "Acuerdo para la

\footnotetext{
${ }^{9}$ Se disolvió la Comisión de Planificación y Coordinación de Inversiones Hidrocarburíferas y se derogaron artículos del Reglamento del Régimen de Soberanía Hidrocarburífera. Esto implicó la eliminación las facultades de esta Comisión de evaluar y monitorear propuestas y planes de inversiones, auditar y fiscalizar costos de producción provistos por las empresas productoras, adoptar medidas correctivas y de prevención de conductas distorsivas y fijar criterios para precios del mercado interno.

${ }^{10}$ En enero de 2017 la Ley $N^{\circ} 26.732$ que habilitaba las retenciones dejó de tener vigencia y no fue prorrogada. Posteriormente, hacia finales del 2018 el gobierno habilitó el cobro de US\$ 4 mediante el Decreto 793/18.
} 
transición a precios internacionales de la industria hidrocarburífera argentina" consistente en un sendero de convergencia para alcanzar gradualmente el precio de paridad (Ministerio de Hacienda, 2018a). Se desestructuró el esquema de programas de estímulo, no renovándose los planes Gas I y II, que finalizaban en el año 2017.

Este marco se combinó con la caída en el valor internacional de los hidrocarburos. El precio internacional del barril había comenzado a descender a partir del 2014, alcanzando su caída más pronunciada en el 2015 y continuando con valores bajos hasta 2017 cuando comienza a mejorar (Ministerio de Hacienda, 2018a). Esta situación, junto a la eliminación del precio sostén, configuró un nuevo escenario en el cual se produjo una fuerte reducción en el nivel y el ritmo de la inversión en exploración y explotación, impactando en el empleo directo e indirecto (Landriscini, 2017, 2018). Las empresas operadoras, incluida YPF, y las grandes prestadoras de servicios, recurrieron a las suspensiones, retiros anticipados y cancelaciones de contratos (Daicz y Monlezún, 2016; Schinelli, et al., 2019; "YPF bajará 33", 1 de noviembre de 2016). En cuanto al panorama general, respecto a la producción en el país, en el caso del petróleo, entre 2016 y 2018 se produjo una caída del 4\%. En el caso del gas la tendencia al alza se mantuvo con un aumento del $5 \%$, con base en los no convencionales, que fueron estimulados a través de un entramado de políticas y programas específicos (Pérez Roig, 2018).

En relación a la empresa bajo control estatal, desde el gobierno se postuló que YPF debía tener una dinámica de funcionamiento equivalente al resto de las empresas del sector (Landriscini, 2017). La nueva gestión de la empresa postuló una política centrada en el aumento de la productividad a partir de la reducción de los costos de funcionamiento y estructura. En esta línea, se implementó un "programa de mejora de la eficiencia organizacional" que implicó un recorte del personal (YPF, 2016). En consonancia, en el año 2016, se produjo la disminución en un 14\% de los trabajadores totales de la empresa, respecto al 2015 (YPF, 2016). La caída más fuerte del empleo se da en dicho año, para luego recuperarse brevemente en el siguiente, pero manteniendo una cantidad menor que la etapa previa. En cuanto al personal de las contratistas se redujo en un 15\%, entre 2016 y 2018 (YPF, 2018). A su vez, se realizó una revisión de los contratos con las empresas proveedoras de servicios, se disminuyeron los precios acordados y se produjeron aplazos en los pagos, lo que significó problemas para la cancelación de los salarios ("YPF achica inversiones", 5 de marzo de 2016).

Los resultados de producción de la empresa evidencian una baja de la actividad en relación con el período anterior y la priorización de la producción de gas, en especial no convencional. Respecto a la producción total, en cuanto al petróleo, se registró una caída del $2 \%$ entre el año 2016 y 2018. ${ }^{11}$ En el caso del gas, se mantuvo la tendencia alcista, con un aumento del 5\% para dichos años. Este se relaciona principalmente con la explotación en la Cuenca Neuquina. Para el Golfo San Jorge, la producción de YPF registra, en el caso del petróleo, una caída del $10 \%$, mientras que, para el gas, se mantiene la producción, pero con un crecimiento menor (4\%). Si observamos la participación de YPF en el total de la producción del Golfo, para el año 2018, identificamos una disminución en la misma en un 1\% tanto en caso del petróleo $(38 \%)$ como en el gas (51\%). Se evidencia un retroceso en los equipos de perforación activos. En el caso de la exploración, a nivel país se redujo a 29 el número de equipos para el año 2016. Entre este año y 2018 se produjo una caída del 48\%. En el caso de la explotación se paso de un total de 719 pozos en el año 2015 a un total de 365 en el 2018. En la cuenca en estudio también se observa una tendencia descendente en materia de exploración y explotación de la empresa. Los pozos perforados para exploración disminuyen a 3 y los de explotación a 94, para el año 2018.

${ }^{11} \mathrm{Al}$ momento de escritura del presente artículo, aún no se encontraban disponibles los datos correspondientes a 2019. 
Ahora bien, ante los procesos mencionados en el sector y la empresa durante el período en estudio, nos planteamos las siguientes preguntas: ¿Cómo se desarrolló la conflictividad de los trabajadores vinculada a la empresa? y ¿Qué cambios y continuidades se produjeron entre las distintas etapas privada y bajo control estatal y las gestiones de ésta última? Avancemos entonces en cómo se desenvolvieron los conflictos de los trabajadores en torno a la empresa. En primer lugar, realizamos una caracterización general de la conflictividad para luego abordar la evolución de las principales dimensiones de los episodios contenciosos durante el período abordado.

\subsection{Características generales de la conflictividad}

\subsubsection{Distribución geográfica.}

Como observamos en la Tabla $\mathrm{N}^{\circ} 1,58 \%$ de los episodios transcurren en la región norte de la provincia de Santa Cruz, $21 \%$ en la región del Chubut y mismo porcentaje de episodios de manera simultánea en ambas provincias (21\%). La mayor conflictividad registrada en Santa Cruz, deviene del hecho de que, como mencionamos, YPF es la principal operadora dicha provincia, aportando el 59\% de la producción de petróleo de la misma. Le sigue SINOPEC con el 24\% y Panamerican Energy con el 10\%. (Ministerio de Hacienda, 2018a, 2018b). Mientras que, en el caso del Chubut, YPF se encuentra en segundo lugar, aportando el $22 \%$ del petróleo, detrás de Panamerican Energy, que representa el $61 \%$ de la producción de dicha provincia, con base en el yacimiento Cerro Dragón (Ministerio de Hacienda, 2017, 2018a).

Tabla $N^{\circ} 1$. Localización episodios contenciosos. YPF. CGSJ (2003-2019)

(Respuesta múltiple con base en la totalidad de los episodios contenciosos N:164).

\begin{tabular}{|c|c|}
\hline Localización & Porcentaje \\
\hline Santa Cruz & $58 \%$ \\
\hline Chubut & $21 \%$ \\
\hline Ambas (CGSJ) & $21 \%$ \\
\hline Total & $100 \%$ \\
\hline
\end{tabular}

Fuente: Base YPF. Elaboración propia. IIGG. UBA.

\subsubsection{Principales actores protagonistas de los episodios conflictivos.}

Existe una multiplicidad de actores que interpelan a la empresa en pos de demandas vinculadas con problemáticas del mundo del trabajo, tal como se observa en el Gráfico $\mathrm{N}^{\circ} 1$. En primer lugar, quienes mayoritariamente participaron en episodios de conflictos, son los sindicatos petroleros privados de base (79\% de los episodios). Estos agrupan a los trabajadores operarios, administrativos, de maestranza y/o de servicios auxiliares que desempeñan tareas en las empresas privadas y subsidiarias dedicadas a la extracción, industrialización y comercialización de petróleo y gas. En el Golfo San Jorge, los sindicatos petroleros de base organizan su ámbito de representación de acuerdo con el territorio provincial (Sindicato Petrolero y del Gas Privados de Santa Cruz y Sindicato del Petróleo y Gas Privados del Chubut.)

En segundo lugar, se encuentran los trabajadores de mayor categoría en cuanto a jerarquía (21\% de los episodios). Los sindicatos de este segmento agrupan a todo el personal jerárquico, idóneo y profesional, en relación de dependencia, que desarrollen tareas en las empresas privadas y subsidiarias, cuyo objeto sea la exploración, explotación, industrialización y comercialización de productos y subproductos del petróleo, gas y la petroquímica. En la CGSJ se desenvuelve el Sindicato del Personal Jerárquico y Profesional de la Patagonia Austral. 
Luego, emergen los trabajadores desocupados de la actividad petrolera, que ocupan el tercer lugar en la participación en episodios de conflicto (10\%). Se trata de grupos de trabajadores desempleados del sector (no incluye a despedidos recientes). Poseen distinto nivel de organización, abarcando desde conjuntos conformados coyunturalmente a colectivos más organizados con relativa duración en el tiempo.

Seguidamente, se encuentran los trabajadores de la construcción (6\% de los episodios), que realizan obras de ingeniería o arquitectura dentro de los yacimientos. Estos se agrupan mayormente en la Unión Obrera de la Construcción de la República Argentina (UOCRA), mediante sus dependencias provinciales. Con porcentajes menores aparecen los trabajadores camioneros, que prestan servicios de transporte y/o logística en los yacimientos y participaron del 2\% de los episodios. Los agrupa el Sindicato de Trabajadores Camioneros, Obreros y Empleados del Transporte Automotor de Cargas, Logística y Servicios, con sus filiales. Asimismo, los trabajadores directos de YPF asumen un porcentaje marginal con un $2 \%$ de participación en episodios contenciosos

Gráfico $\mathrm{N}^{\circ}$ 1. Principales protagonistas de los episodios contenciosos, 2003-2019 (Respuesta múltiple con base en la totalidad de los episodios contenciosos N: 164 episodios).

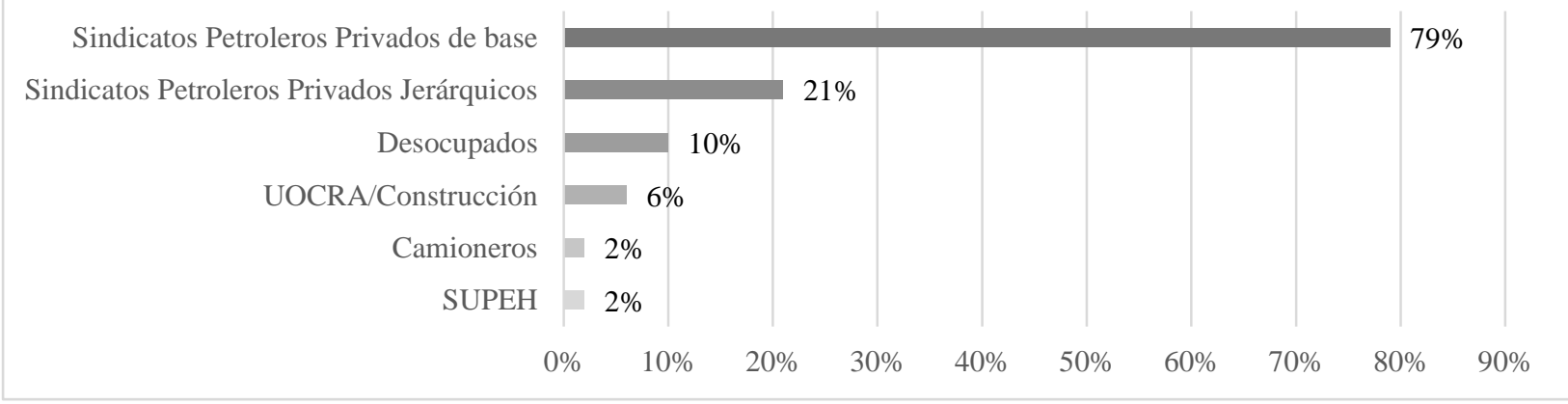

Fuente: Base YPF. Elaboración propia. IIGG. UBA

La configuración de actores que participan en episodios de conflicto en torno a YPF, se corresponde con las características que asume la forma de organización del proceso de trabajo en la empresa. A partir de la privatización de YPF y luego de una gran reducción del personal, se conformó un esquema de organización laboral sustentado en la descentralización y fragmentación del proceso productivo, mediante la aplicación de estrategias de tercerización y subcontratación laboral (Orlansky y Makón, 2003; Muñiz Terra, 2008; Figari y Palermo, 2009, Prado y Robledo, 2015a). El modelo de organización resultante se caracteriza por la articulación de distintas empresas en torno a diversas actividades complementarias al mismo proceso productivo (Cynuel, 2019). YPF en su carácter de operadora, es la concesionaria de explotación de los yacimientos y mantiene el control sobre la organización del proceso y las decisiones productivas y de inversión. A su vez, la empresa externaliza actividades mediante la contratación de grandes empresas de servicios petroleros, también denominadas como de operaciones especiales, en su mayoría de capital internacional. Un tercer segmento de subcontratación está conformado por las PyMEs de servicios petroleros, de capital nacional y de carácter regional, que son contratadas por la operadora y las grandes prestadoras de servicios, dando lugar a una subcontratación en cadena (Cynuel, 2019). Este sector es el de mayor volumen en cuanto a cantidad de empresas y empleo. Las PyMEs se encuentran en una posición de dependencia con la operadora por lo que adecuan su funcionamiento a los requerimientos de las mismas (Prado y Robledo, 2015a).

En suma, el esquema involucra a una multiplicidad de empresas interdependientes entre sí articuladas en función del desarrollo de un mismo proceso de producción. Lo distintivo, es que no hay una fragmentación espacial de dicho proceso, sino que, la tercerización se realiza en el mismo espacio y dentro de la misma empresa (Muñiz Terra, 2008). Así, los vínculos 
entre empresas y el rol de YPF aparecen con claridad para los empleados de las contratistas. En adición, de acuerdo con el artículo 30 de la Ley de Contrato de Trabajo ( $\mathrm{N}^{\circ}$ 20.744), la empresa principal tiene la responsabilidad de controlar el cumplimiento de las obligaciones de las contratistas o subcontratistas.

En términos de empleo, la reducción del personal de la YPF estatal y la estrategia de tercerización laboral, generaron que la mayor cantidad de trabajadores se aglutinen en las empresas contratistas y subcontratistas de la actividad (Muñiz Terra, 2012). Al considerar el total de empleados vinculados con YPF, incluyendo directos, de sus empresas controladas y contratistas, estos últimos representan el 67\% (YPF, 2018). Por esta serie de razones, la mayor proporción de los conflictos son protagonizados por los trabajadores de las empresas contratistas que prestan servicios a YPF y no por trabajadores directos de la misma.

Por otro lado, la tercerización y la subcontratación concentra en un mismo proceso empleados de distintas empresas, que se encuentran encuadrados en diferentes sindicatos (Landriscini, 2015, 2019). Es así que interpelan a YPF en sus reclamos distintas asociaciones gremiales, en función de las actividades en las que los trabajadores están involucrados.

Como mencionamos, otro de los principales actores protagonistas del conflicto vinculado a la empresa refiere a trabajadores desocupados de la actividad petrolera, que ocupan el tercer lugar en la participación en episodios de conflicto, como se mencionó anteriormente. En este sentido, es importante destacar el rol central que ocupó YPF en las localidades en las que desarrolló y desenvuelve aún la actividad, tanto como proveedora de empleo, como de infraestructura y servicios para la comunidad (Salvia, 1999, Palermo, 2012, 2013). Asimismo, YPF es una de las empresas más grandes del sector, tanto en cuanto a actividad productiva como en materia de empleo.

\subsubsection{La evolución de los episodios contenciosos durante los años 2003-2019}

El total de episodios contenciosos protagonizados por trabajadores en torno a YPF registrados es de 164 con una media anual de 10 episodios durante el período 2003-2019. Como se puede observar en el Gráfico $\mathrm{N}^{\circ} 2$, estos no mantienen una tendencia homogénea y similar durante el período en estudio, sino que podemos observar variaciones entre los mismos. Identificamos tres momentos de intensificación en los conflictos. El primero en el año 2009, seguido por el año 2011. Luego, con mayor intensidad entre el año 2016 y parte del 2017. Ahora bien, al poner el foco en las demandas y los protagonistas de la acción, observamos también modificaciones en los mismos, como veremos a continuación. Distinguimos cuatro etapas distintivas que es posible relacionar con los cambios en la política sectorial y en YPF, reseñados anteriormente. La primera abarca desde el año 2003 al año 2007, la segunda desde el año 2008 al 2011. Luego, una tercera etapa transcurre entre los años 2012 y 2015 y una última y cuarta etapa entre 2016 y 2019.

Gráfico $N^{\circ}$ 2. Evolución de los episodios contenciosos durante los años 2003-2019. N: 164

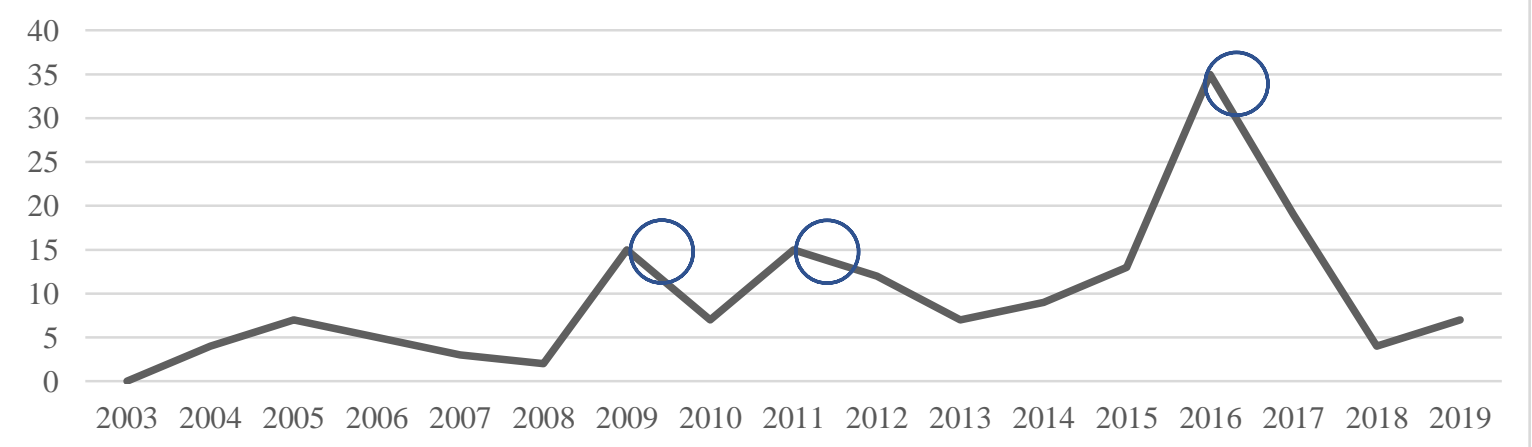

Fuente: Base YPF. Elaboración propia. IIGG. UBA. 


\subsection{Las etapas de la conflictividad}

\subsubsection{Disputas salariales en YPF bajo el capital privado (2003-2007)}

Entre los años 2003 y 2007 se observan niveles estables y bajos en los episodios de conflicto, con una media anual de 4 episodios contenciosos. Como se muestra en la Tabla $\mathrm{N}^{\circ} 2$, observamos que el conflicto fue llevado adelante por los principales sindicatos del sector, tanto de base ( $84 \%$ de los episodios) como jerárquicos (5\% de los episodios). Participan también de la conflictividad, los trabajadores desocupados (21\% de los episodios).

En estos años, la principal reivindicación radicó en los pedidos de aumentos salariales (74\% de los episodios). Nos referimos a mejoras en la remuneración, tanto mensual como en montos e ítems particulares del salario. Seguido a esto, surgen pedidos por puestos de trabajo ( $21 \%$ de los episodios) y las deudas salariales (11\%).

Los tipos de acción empleados por los actores denotan el predominio de la utilización de medidas institucionalizadas. En primer lugar, aparece la suspensión de la producción, mediante el paro y otras formas como la retención de servicios (53\% de los episodios). Esta es una herramienta clásica de los trabajadores asalariados. Su fuerza radica en las consecuencias de la interrupción del proceso productivo. Tiene altos niveles de institucionalización, al encontrarse inscripta jurídicamente y contar con procedimientos específicos para su desarrollo. En segundo lugar, aparecen los bloqueos a instalaciones productivas de la empresa (32\% de los episodios). Abarca aquellos casos en los que se ocupa o se bloquea el acceso a las instalaciones de trabajo, impidiendo el ingreso y por lo tanto el proceso productivo (pozos, yacimientos, espacios productivos, etc). Esta forma de acción cuenta con un alto carácter disruptivo y traspasa los marcos normativos, por lo que puede acarrear consecuencias legales. El bloqueo a instalaciones corresponde principalmente a los trabajadores desocupados, siendo su principal forma de acción en esta etapa (75\% de los episodios). En tercer lugar, aparecen los anuncios de medidas de fuerza ( $21 \%$ de los episodios). Son acciones declarativas, que pueden contemplar el anuncio de distintas formas de acción, desde el paro, la retención de servicios, hasta el bloqueo de instalaciones y de vehículos petroleros de la empresa. No conllevan una alteración del orden, sin embargo, la proclamación de una medida tentativa actúa como una amenaza potencial, al representar las posibles consecuencias que tendría su efectiva realización.

Como vimos, en estos años, la actividad de la empresa mantuvo una cierta estabilidad, sin registrarse momentos de caída abrupta. En este marco, el conflicto se produjo en torno a demandas propias de la lucha corporativa, como son los aumentos salariales, esgrimidos por los principales sindicatos del sector. Las confrontaciones se dirimieron a través de formas de acción clásicas de la clase trabajadora como el paro. Mientras que quienes se ven imposibilitados de hacerlo, como los trabajadores desocupados, recurrieron al bloqueo a instalaciones. La Tabla $\mathrm{N}^{\circ} 2$ expresa las características principales de la conflictividad en esta primera etapa, en cuanto a los actores protagonistas, demandas y formas de acción. ${ }^{12}$

\footnotetext{
${ }^{12}$ Tanto para el análisis realizado en el escrito como en los cuadros se presentan para cada variable los tres primeros valores que dan cuenta de la mayor incidencia en los casos.
} 
Tabla $N^{\circ}$ 2. Principales actores, demandas y formas de acción. Etapa 1 (2003-2007). YPF. CGSJ.

(Respuesta múltiple con base en la totalidad de los episodios contenciosos. N:164).

\begin{tabular}{|c|c|c|}
\hline Actor & Etapa 1 (2003-2007) & Forma de acción \\
\hline $\begin{array}{c}\text { Petroleros privados operarios } \\
(84 \%)\end{array}$ & Aumentos salariales $(\mathbf{7 4 \% )})$ & $\begin{array}{c}\text { Suspensión de la } \\
\text { producción }(53 \%)\end{array}$ \\
\hline $\begin{array}{c}\text { Trabajadores desocupados } \\
(21 \%)\end{array}$ & $\begin{array}{c}\text { Pedidos por puestos de } \\
\text { trabajo }(21 \%)\end{array}$ & $\begin{array}{c}\text { Bloqueos a instalaciones } \\
(32 \%)\end{array}$ \\
\hline $\begin{array}{c}\text { Petroleros privados jerárquicos } \\
(5 \%)\end{array}$ & Deudas salariales $(11 \%)$ & $\begin{array}{c}\text { Anuncios de medidas de } \\
\text { fuerza }(21 \%)\end{array}$ \\
\hline
\end{tabular}

Fuente: Base YPF. Elaboración propia. IIGG. UBA.

\subsubsection{Conflicto defensivo ante la caída de la actividad (2008 - 2011)}

La segunda etapa identificada, registra un aumento en la intensidad y recurrencia de los episodios contenciosos, con una media anual de 10 y dos picos en el conflicto (2009 y 2011).

El período que abarca los años entre 2008 y 2011, denota un predominio de conflictividad defensiva ante los despidos y suspensiones llevados adelante por la empresa. Así, se produce una reconfiguración distintiva en las demandas. Como se puede observar en la Tabla $\mathrm{N}^{\circ} 3$, asumen los primeros lugares los reclamos por deudas salariales (46\% de los episodios) y los pedidos por la continuidad en el empleo ( $41 \%$ de los episodios). En menor medida aparecen demandas de carácter institucional por problemas en el encuadramiento gremial y el reconocimiento de los convenios colectivos correspondientes (26\% de los episodios). Los pedidos de aumentos en el salario disminuyen drásticamente 56 puntos porcentuales, pasando a asumir el $18 \%$ de los episodios.

Quienes impulsaron el rechazo a la caída de la actividad en la empresa, son los principales sindicatos del sector. Los sindicatos petroleros privados operarios (59\% de los episodios) y jerárquicos (23\% de los episodios), a los que se suman los sindicatos de la construcción (10\% de los episodios), evidenciando una unión entre los trabajadores de distintas actividades y jerarquías, en pos de la articulación de demandas.

Respecto a las formas mediante las cuales se desarrollaron las confrontaciones, observamos que estas adquieren un matiz más disruptivo, mediante el empleo de tipos de acción que rebasan los canales formales de procesamiento del conflicto (Tabla $\mathrm{N}^{\circ} 3$ ). Así, el bloqueo a instalaciones productivas de la empresa asume el primer lugar (41\% de los episodios). Seguido por la suspensión de la producción mediante el paro (33\% de los episodios). Luego, asume valores más altos (18\% de los episodios), otra forma de acción no mediada institucionalmente, el bloqueo a vehículos petroleros de la empresa. Se trata de la interrupción del tránsito a través de bloqueos en rutas o caminos de acceso a yacimientos y/o pozos, impidiendo el paso de vehículos de la empresa. Mismo porcentaje registra el anuncio de medidas de fuerza.

Como mencionamos en los inicios del año 2009 se da un pico en el conflicto, más particularmente en el primer semestre del mismo. Momento en el cual se registra una fuerte caída de la actividad que redundó en despidos, suspensiones y bajas de equipos de trabajo. Observemos con más detalle las características de este pico en la conflictividad. Tal como muestra la tabla $\mathrm{N}^{\circ} 3$, los sindicatos petroleros de base son los protagonistas de la intensificación de las confrontaciones (60\% de los episodios) acompañados en menor medida por los petroleros jerárquicos (20\% de los episodios). El pico se produjo en claro rechazo a la caída de la actividad, siendo la principal demanda la continuidad en el empleo (73\% de los 
episodios). Seguido por las deudas en montos salariales (40\% de los episodios). Las confrontaciones adquieren un matiz más disruptivo. Si bien la principal acción empleada es la amenaza de medidas de fuerza (40\% de los episodios), los bloqueos a instalaciones de la empresa cobran fuerza con un $33 \%$, asimismo se producen bloqueos a vehículos petroleros (13\%). Los paros aparecen en tercer lugar, con un 33\%. El pico de conflicto ilustra con claridad la fuerte reacción ante la disminución de la actividad, llevada adelante por los principales sindicatos del sector a través de medidas institucionalizadas, pero también con un incremento de formas de acción de carácter más disruptivo como los bloqueos a instalaciones y vehículos de la empresa.

Ahora bien, en el año 2011, también se registra un momento de intensificación de los conflictos. Este pico en la conflictividad, es protagonizado, por un lado, por los sindicatos petroleros de base (50\% de los episodios) y por los trabajadores de la construcción (20\% de los episodios). Las demandas giran en torno a una multiplicidad de reivindicaciones; en primer lugar, las deudas salariales (40\% de los episodios), seguidas por exigencias de aumentos salariales (20\% de los episodios), demandas por problemáticas de encuadramiento y representación y pedidos de puesto de trabajo ( $20 \%$ de los episodios, cada una). Se denota así una mayor heterogeneidad en los ejes del conflicto. En este sentido, no se registra una unidad de diversos actores en torno a las mismas demandas, sino que se produce más bien una concentración en el tiempo de episodios conflictivos con base a distintas reivindicaciones. Al profundizar en los episodios más distintivos, observamos que aquellos protagonizados por los sindicatos petroleros de base, corresponden mayoritariamente al Sindicato Petróleo y Gas Privados de Santa Cruz. Estos se producen en su mayoría en torno a un desacuerdo respecto a la aceptación de la cifra de aumento salarial ofrecida por YPF y el resto de las operadoras y aceptada por la conducción del gremio. En relación a esto, se abrió una interna en el mismo, que derivó en la suspensión de la producción y el bloqueo a instalaciones y vehículos, principalmente de YPF (Arias, 2011a). ${ }^{13}$ Esto también se vinculó con otros episodios, ya que, la empresa luego se negó al pago de los días no trabajados, dando lugar a la movilización de los trabajadores en pos de la exigencia del cobro de los mismos (Arias, 2011b).

Por otro lado, trabajadores de la construcción en Chubut protagonizaron distintas confrontaciones en este momento de intensificación de las disputas. Las mismas se relacionan con reclamos en torno a salarios adeudados por la empresa, que derivaron en la paralización de su producción a través de distintas medidas ("Hay más bloqueos", 17 de mayo de 2011).

Así, a diferencia del primer pico conflictivo, en este momento se concentraron temporalmente diferentes disputas de diversos actores que involucraron a la empresa. Respecto a las medidas empleadas para llevar adelante las reivindicaciones, éstas asumen un carácter disruptivo y que rebasa los marcos normativos de la protesta, a partir del bloqueo a instalaciones productivas (50\% de los episodios) y a vehículos petroleros (40\% de los episodios). El paro es también empleado, pero en menor medida (30\% de los episodios).

En suma, como se observa en la Tabla $\mathrm{N}^{\circ} 3$, los años que abarcan la segunda etapa registran un aumento de las confrontaciones, principalmente en relación a la caída de la actividad. Las confrontaciones adquieren un matiz más disruptivo a través de medidas como el bloqueo a instalaciones de la empresa.

\footnotetext{
${ }^{13}$ Esta situación derivó en la intervención judicial del gremio, que hasta ese momento estuvo a cargo de Héctor Segovia. La intervención se mantuvo hasta el año 2013, cuando se celebraron elecciones, dando lugar a una nueva conducción con Claudio Vidal como Secretario General. El mismo fue re-elegido y mantiene en la actualidad la conducción del sindicato ("Intervención de petroleros", 26 de octubre 2011; "Alto porcentual de" 20 de noviembre de 2013; "Claudio Vidal ganó", 22 de septiembre de 2017)
} 
Tabla N 3. Principales actores, demandas y formas de acción. Etapa 2 (2008-2011). YPF. CGSJ.

(Respuesta múltiple con base en la totalidad de los episodios contenciosos. N: 164).

\begin{tabular}{|c|c|c|}
\hline Actor & Etapa 2 (2008-2011) & Forma de acción \\
\hline $\begin{array}{c}\text { Petroleros privados operarios } \\
(59 \%)\end{array}$ & $\begin{array}{c}\text { Deudas salariales } \\
(46 \%)\end{array}$ & $\begin{array}{c}\text { Bloqueos a instalaciones } \\
(41 \%)\end{array}$ \\
\hline $\begin{array}{c}\text { Petroleros privados jerárquicos } \\
(23 \%)\end{array}$ & $\begin{array}{c}\text { Continuidad en el } \\
\text { empleo }(41 \%)\end{array}$ & $\begin{array}{c}\text { Suspensión de la producción } \\
(33 \%)\end{array}$ \\
\hline $\begin{array}{c}\text { Trabajadores de la } \\
\text { construcción }(10 \%)\end{array}$ & Institucionales $(26 \%)$ & $\begin{array}{c}\text { Bloqueo a vehículos } \\
\text { petroleros y Anuncio de } \\
\text { medidas de fuerza (18\% c/u })\end{array}$ \\
\hline
\end{tabular}

Fuente: Base YPF. Elaboración propia. IIGG. UBA.

\subsubsection{Trabajadores formales y desocupados del sector ante la empresa bajo control estatal (2012-2015)}

En esta tercera etapa, observamos que los niveles de episodios mantienen cierta estabilidad sin grandes fluctuaciones entre los años. Con niveles relativamente mayores respecto a los años previos (exceptuando los picos conflictivos de la anterior etapa), la media es de 11 episodios por año. Como muestra la Tabla $\mathrm{N}^{\circ} 4$, los principales actores protagonistas de las confrontaciones son los petroleros privados de base ( $78 \%$ de los episodios) y los jerárquicos (39\% de los episodios). Al mismo tiempo, emergen con fuerza los trabajadores desocupados del sector (20\% de los episodios). Estos aumentan 12 puntos porcentuales respecto a la etapa previa, asumiendo los valores más altos del período (participan en 8 episodios). Así, la reestatización de la empresa se configuró como una oportunidad para su paso a la acción.

En cuanto a las demandas, como también se puede observar en la Tabla $\mathrm{N}^{\circ} 4$, encontramos un viraje en las mismas que pasan a asumir un carácter ofensivo. Los pedidos de aumentos salariales, ocupan el primer lugar (34\% de los episodios), en pos de recomponer la situación luego del período previo de repliegue. El segundo lugar, corresponde a reclamos por deudas en el salario ( $22 \%$ de los episodios). Y en tercer lugar los pedidos por puestos de trabajo (20\% de los episodios), en consonancia con el aumento de la participación de trabajadores desocupados. Ahora bien, la forma en la que se dirimieron las disputas también presenta modificaciones (Tabla $\mathrm{N}^{\circ}$ 4). Los anuncios de medidas de fuerza pasan a ser la principal forma de acción empleada ( $29 \%$ de los episodios). Seguido por el paro (27\% de los episodios) y las concentraciones y movilizaciones ( $22 \%$ de los episodios). Así, observamos un fuerte repliegue de las formas disruptivas adquiriendo el conflicto un carácter institucional.

La tercera etapa, registra una reconfiguración en las características del conflicto. En el marco de la reactivación de la actividad y el giro en la estrategia productiva de YPF, los trabajadores formales del sector demandan aumentos en su salario. Si bien también se observan reclamos por falta de pagos y deudas salariales. Como vimos, el proceso de recuperación de la actividad evidenció ciertos límites especialmente hacia mediados y fines del 2015. Por su parte, los desocupados incrementan su accionar en pos de pedidos a la empresa por la solución de su situación de desempleo. El conflicto, a su vez, se institucionaliza, a través de medidas que no suponen la suspensión de la producción, como los anuncios y las concentraciones y las que si implican su interrupción, lo hacen a través de canales formales, como el paro. 
Tabla $N^{\circ}$ 4. Principales actores, demandas y formas de acción. Etapa 3 (2012-2015). YPF. CGSJ.

(Respuesta múltiple con base en la totalidad de los episodios contenciosos. N:164).

\begin{tabular}{|c|c|c|}
\hline Actor & Etapa 3 (2012-2015) & Fomanda \\
\hline $\begin{array}{c}\text { Petroleros privados operarios } \\
(78 \%)\end{array}$ & Aumentos salariales $(34 \%)$ & $\begin{array}{c}\text { Anuncios de medidas de } \\
\text { fuerza }(29 \%)\end{array}$ \\
\hline $\begin{array}{c}\text { Petroleros privados jerárquicos } \\
(39 \%)\end{array}$ & Deudas salariales $(22 \%)$ & $\begin{array}{c}\text { Suspensión de la } \\
\text { producción }(27 \%)\end{array}$ \\
\hline $\begin{array}{c}\text { Trabajadores desocupados } \\
(20 \%)\end{array}$ & Puestos de trabajo (20\%) & $\begin{array}{c}\text { Concentraciones y } \\
\text { movilizaciones }(22 \%)\end{array}$ \\
\hline
\end{tabular}

Fuente: Base YPF. Elaboración propia. IIGG. UBA.

4.3.4 Movilización de los trabajadores en rechazo de la caída de la actividad (2016-2019).

En los últimos años del período observamos una intensificación de las confrontaciones. La etapa que abarca desde el año 2016 a junio de 2019 concentra la media más alta (18). Si observamos la composición del conflicto, como se muestra en la Tabla $\mathrm{N}^{\circ} 5$, en cuanto a los actores, los petroleros privados de base asumen el protagonismo ( $91 \%$ de los episodios), junto a los trabajadores jerárquicos (19\% de los episodios) y los de la construcción (8\% de los episodios). Se observa, asimismo, un giro en las demandas esgrimidas hacia la defensa de los puestos de trabajo (Tabla $\mathrm{N}^{\circ}$ 5). Así, en $79 \%$ de los episodios se refiere a demandas por la continuidad del empleo. Seguidos por las deudas salariales $15 \%$ de los episodios y pedidos por puestos de trabajo (8\% de los episodios). El rechazo a la caída de la actividad se produjo tanto mediante medidas institucionalizas como con mayor potencial disruptivo (Tabla $\mathrm{N}^{\circ} 5$ ). Los anuncios de medidas de fuerza ( $28 \%$ de los episodios), la suspensión de la producción mediante el paro (25\% de los episodios) y las declaraciones y comunicados $(25 \%$ de los episodios. Cabe destacar que los bloqueos a instalaciones productivas de la empresa (22\% de los episodios), aumentan en un $43 \%$ respecto a la etapa previa.

Como mencionamos entre el año 2016 y principios de 2017, se produce un pico en el conflicto, con mayor intensidad y duración en el tiempo que los correspondientes al 2009 y 2011. Este momento de intensificación de las disputas se dio en claro rechazo a la caída de la actividad, siendo la principal demanda la continuidad laboral ( $82 \%$ de los episodios), seguida por los reclamos de salarios adeudados (17\% de los episodios). Quienes llevan adelante el ciclo conflictivo son los principales sindicatos del sector, los petroleros privados de base (94\% de los episodios), los trabajadores jerárquicos (19\% de los episodios) y así también los trabajadores de la construcción ( $7 \%$ de los episodios). Las medidas empleadas abarcan tanto acciones enunciativas, como las declaraciones públicas y conferencias de prensa ( $28 \%$ de los episodios) y el anuncio de medidas de fuerza ( $26 \%$ de los episodios), así como formas de acción que suponen la suspensión de la producción, mediante el paro ( $24 \%$ de los episodios) y a partir de formas menos institucionales como el bloqueo a instalaciones (24\% de los episodios).

La última etapa del período asume un carácter claramente defensivo, en el que los principales sindicatos del sector, junto a quienes realizan tareas periféricas al proceso central, como los trabajadores de la construcción, se movilizan en pos de la defensa de los puestos de trabajo, a través de medidas que combinas formas institucionalizadas con aquellas que denotan un mayor carácter disruptivo. 
Tabla $N^{\circ}$ 5. Principales actores, demandas y formas de acción. Etapa 4 (2016-2019). YPF.

CGSJ.

(Respuesta múltiple con base en la totalidad de los episodios contenciosos. N:164).

\begin{tabular}{|c|c|c|}
\hline Actor & Etapa 4 (2016-2019) & Forma de acción \\
\hline $\begin{array}{c}\text { Petroleros privados operarios } \\
(91 \%)\end{array}$ & $\begin{array}{c}\text { Continuidad del empleo } \\
(79 \%)\end{array}$ & $\begin{array}{c}\text { Anuncios de medidas de } \\
\text { fuerza }(28 \%)\end{array}$ \\
\hline $\begin{array}{c}\text { Petroleros privados } \\
\text { jerárquicos (19\%) }\end{array}$ & Deudas salariales $(15 \%)$ & $\begin{array}{c}\text { Suspensión de la } \\
\text { producción }(25 \%)\end{array}$ \\
\hline $\begin{array}{c}\text { Trabajadores de la } \\
\text { construcción }(8 \%)\end{array}$ & Puestos de trabajo $(8 \%)$ & $\begin{array}{c}\text { Declaraciones/comunicados } \\
(25 \%)\end{array}$ \\
\hline
\end{tabular}

Fuente: Base YPF. Elaboración propia. IIGG. UBA.

En la Tabla $\mathrm{N}^{\circ} 6$ se presentan de modo comparativo las características centrales de la conflictividad en cada etapa durante el período 2003-2019, de acuerdo a los actores, demandas y formas de acción. Así también la media anual de episodios de conflicto para cada una de ellas.

Tabla $N^{\circ}$ 6. Etapas de la conflictividad según actores, demandas y formas de acción. YPF.

CGSJ (2003-2019)

\begin{tabular}{|c|c|c|c|c|}
\hline & $\begin{array}{c}\text { Etapa } 1 \\
(2003-2007)\end{array}$ & $\begin{array}{c}\text { Etapa } 2 \\
(2008-2011)\end{array}$ & $\begin{array}{c}\text { Etapa } 3 \\
(2012-2015)\end{array}$ & $\begin{array}{c}\text { Etapa } 4 \\
(2016-2019)\end{array}$ \\
\hline Actores & $\begin{array}{l}\text {-Petroleros } \\
\text { privados } \\
\text { operarios } \\
(84 \%) \\
\text {-Trabajadores } \\
\text { desocupados } \\
(21 \%) \\
\text {-Petroleros } \\
\text { privados } \\
\text { jerárquicos } \\
(5 \%)\end{array}$ & $\begin{array}{l}\text {-Petroleros } \\
\text { privados } \\
\text { operarios } \\
(59 \%) \\
\text {-Petroleros } \\
\text { jerárquicos } \\
(23 \%) \\
\text {-Trabajadores } \\
\text { de la } \\
\text { construcción } \\
(10 \%)\end{array}$ & $\begin{array}{l}\text {-Petroleros privados } \\
\text { operarios }(78 \%) \\
\text {-Petroleros privados } \\
\text { jerárquicos }(39 \%) \\
\text {-Trabajadores } \\
\text { desocupados }(20 \%)\end{array}$ & $\begin{array}{l}\text {-Petroleros } \\
\text { privados } \\
\text { operarios }(91 \%) \\
\text {-Petroleros } \\
\text { privados } \\
\text { jerárquicos } \\
(19 \%) \\
\text {-Trabajadores de } \\
\text { la construcción } \\
(8 \%)\end{array}$ \\
\hline Demandas & $\begin{array}{l}\text {-Aumentos } \\
\text { salariales } \\
(79 \%) \\
\text {-Puestos de } \\
\text { trabajo }(21 \%) \\
\text { - } \\
\text { Institucionale } \\
\text { s (11\%) } \\
\text {-Deudas } \\
\text { salariales } \\
(11 \%)\end{array}$ & $\begin{array}{l}\text {-Deudas } \\
\text { salariales } \\
(46 \%) \\
\text {-Continuidad } \\
\text { en el empleo } \\
(41 \%) \\
\text {-Institucionales } \\
(26 \%)\end{array}$ & $\begin{array}{l}\text {-Aumentos } \\
\text { salariales }(34 \%) \\
\text {-Deudas salariales } \\
(22 \%) \\
\text {-Puestos de trabajo } \\
(20 \%)\end{array}$ & $\begin{array}{l}\text {-Continuidad del } \\
\text { empleo }(79 \%) \\
\text {-Deudas } \\
\text { salariales }(17 \%) \\
\text {-Puestos de } \\
\text { trabajo (8\%) }\end{array}$ \\
\hline
\end{tabular}




\begin{tabular}{|c|c|c|c|c|}
\hline \multirow{3}{*}{$\begin{array}{l}\text { Formas de } \\
\text { acción }\end{array}$} & $\begin{array}{l}\text {-Suspensión } \\
\text { de la } \\
\text { producción }\end{array}$ & $\begin{array}{l}\text {-Bloqueos a } \\
\text { instalaciones } \\
(41 \%)\end{array}$ & $\begin{array}{l}\text {-Anuncios de } \\
\text { medidas de fuerza } \\
(29 \%)\end{array}$ & $\begin{array}{l}\text {-Anuncios de } \\
\text { medidas de } \\
\text { fuerza }(28 \%)\end{array}$ \\
\hline & $\begin{array}{l}(53 \%) \\
\text {-Bloqueos a } \\
\text { instalaciones }\end{array}$ & $\begin{array}{l}\text {-Suspensión de } \\
\text { la producción } \\
(33 \%)\end{array}$ & $\begin{array}{l}\text {-Suspensión de la } \\
\text { producción }(27 \%)\end{array}$ & $\begin{array}{l}\text { - Suspensión de } \\
\text { la producción } \\
(25 \%)\end{array}$ \\
\hline & $\begin{array}{l}(32 \%) \\
\text {-Anuncios de } \\
\text { medidas de } \\
\text { fuerza }(21 \%)\end{array}$ & $\begin{array}{l}\text {-Bloqueo a } \\
\text { vehículos } \\
\text { petroleros } \\
(18 \%)\end{array}$ & $\begin{array}{l}\text { movilizaciones } \\
(22 \%)\end{array}$ & $\begin{array}{l}\text {-Declaraciones/ } \\
\text { comunicados } \\
(25 \%)\end{array}$ \\
\hline Media anual & 4 & 10 & 11 & 18 \\
\hline
\end{tabular}

Fuente: Base YPF. Elaboración propia. IIGG. UBA.

\section{REFLEXIONES FINALES}

Como observamos a partir del análisis realizado, la evolución de la conflictividad vinculada a YPF, durante el período en estudio, denota cambios en la cantidad de los episodios y en la forma que asumen en cuanto a las dimensiones analizadas. Identificamos cuatro etapas que es posible relacionar con dos elementos en interacción, los cambios ocurridos en YPF, respecto a su propiedad y en sus estrategias productivas y las trasformaciones político-institucionales vinculadas al sector. Así, observamos que, los cambios en el sector y en la empresa estructuran el campo en el cual se desarrollan las confrontaciones.

Durante la gestión privada de YPF, predomina una estrategia de valorización del recurso en el corto plazo a través de la sobreexplotación de los pozos existentes y el recorte de las inversiones. Desde la política pública se combina el aumento del control sobre el sector, pero con la permanencia aún de marcos normativos laxos, junto al despliegue de medidas de estímulo, que no logran romper la mencionada dinámica. No obstante, en una primera etapa, en un contexto de altos precios de los hidrocarburos, persiste una cierta estabilidad en la actividad. La conflictividad se despliega a partir de la lucha corporativa de los principales sindicatos del sector, que pujan por mejoras salariales mediante medidas clásicas como el paro. En una segunda etapa bajo el capital privado, se hacen evidentes las consecuencias del predominio de la estrategia centrada en la valorización del recurso. Ante un contexto en el que disminuye la posibilidad de aumentar la rentabilidad, la empresa recurre a estrategias que afectan el empleo, como la baja de equipos y despidos para amortizar costos. Frente a esto la conflictividad adquiere un matiz defensivo y los trabajadores protagonizan una intensificación de las confrontaciones.

Una nueva etapa se abre con la re-estatización parcial de YPF y la conformación de un nuevo entramado regulatorio de la actividad. En el contexto de políticas de estímulo a las inversiones y la producción, la empresa inicia un ciclo inversor que lleva a la recuperación de sus indicadores y estimula el empleo. Se configura un escenario que se conforma como una oportunidad para el paso a la ofensiva de los principales sindicatos del sector, a través de un cambio cualitativo en las demandas, en búsqueda de mejoras en la situación salarial. Asimismo, disminuye la profundidad de las confrontaciones a través del predomino de acciones declarativas e institucionalizadas que no llegan a afectar la producción. Un aspecto novedoso radica en el crecimiento de la participación de los trabajadores desocupados. El aumento de la actividad de la empresa favorece el incremento de su participación en los episodios de conflicto, en pos de demandas por puestos de trabajo. 
Finalmente, en los últimos años estudiados, el cambio de gestión a nivel nacional y en la empresa prioriza una orientación hacia el mercado. Se impulsa una desregulación sectorial y se postula una mayor desvinculación entre la empresa y la política pública. En este contexto, se da una fuerte caída de la actividad, en el sector y en la empresa, que da pie a un ciclo de protesta que une en la lucha por la continuidad laboral a los principales sindicatos petroleros y a aquellos que realizan tareas periféricas en la empresa, a través de medidas de acción directa. El recambio gubernamental a nivel nacional abre una nueva etapa marcada por la asunción de una fuerza política con una orientación contrastante a la del período previo y el inicio de una nueva gestión en YPF. Una serie de interrogantes surgen al respecto; ¿Qué rol asumirá el Estado en el sector?, ¿Qué orientación productiva llevará adelante la empresa y en la región en particular?, ¿Cómo esto afectará a los trabajadores a ella vinculados? y ¿Qué características asumirá la conflictividad del trabajo vinculada a la empresa?

\section{AGRADECIMIENTOS}

Agradezco a la Unidad Académica Río Gallegos de la Universidad Nacional de la Patagonia Austral y a su decano Guillermo Melgarejo, por brindarme la posibilidad de realizar una estancia de investigación en la ciudad de Río Gallegos, que me permitió establecer contacto con investigadores en la temática, así como realizar distintas entrevistas con informantes clave, que contribuyeron a la investigación volcada en el presente artículo. En este sentido, agradezco, por los comentarios, las lecturas sugeridas y los consejos pertinentes y comprometidos a Carlos Vacca, Lourdes Villanueva y Daniel Schinelli.

Asimismo, agradezco a la Facultad de Ciencias Sociales de la Universidad de Buenos Aires por otorgarme el financiamiento para la realización de dicha estancia.

Por último, agradezco a los evaluadores por los valiosos comentarios y sugerencias que contribuyeron a nutrir al presente artículo. Así también, a Candela Hernández y Virginia Nessi por las sugerencias y lectura del mismo. Se los exime de cualquier error u omisión.

\section{BIBLIOGRAFÍA}

ACCONCIA, L. y ALVAREZ, V. (2008). El ser ypefiano. Una identidad al abrigo de la Empresa (o una identidad territorializada) en Ruiz, J.D. (coord.) (2008) Petróleo y región austral. Saberes del trabajo y educacióntécnica. Reconfiguraciones y nuevas subjetividades. Editorial Dunken

BARNEIX, P. (2016). Un repaso de las principales transformaciones en la explotación de hidrocarburos en el periodo 1989-2015. Realidad económica, 304, pp. 1-22.

BARRERA, M. (2011). Análisis del Proceso de Fragmentación y Privatización de YPF: Un Estudio de su Transformación en el Marco de la Desregulación del Mercado Primario de Hidrocarburos (1989-1999). (Tesis de Maestría), FLACSO, Argentina

BARRERA, M. (2012). "Subexploración y sobreexplotación: la lógica de acumulación del sector hidrocarburífero en Argentina". Apuntes para el Cambio, 2, 19-35.

BARRERA, M. (2013). "Reformas estructurales y caída de reservas hidrocarburíferas: el caso argentino". Análisis Económico Núm. 69, vol. XXVIII

BARRERA, M., KENNEDY, D., PALERMO, H. y SCHORR, M. (2015). Impacto socioeconómico de YPF desde su renacionalización (Ley 26.741). Desempeño productivo e implicancias sobre los mercados laborales y el entramado de proveedores. Documento de Proyecto, 1. Comisión Económica para América Latina y el Caribe. 
BUCCI, S., JONES, A. y HERRERA, C. (2017). Impacto de la coyuntura petrolera internacional en la Cuenca del Golfo San Jorge (CGSJ). En el quinquenio 2011 a 2015 y primero trimestre de 2016. Universidad Nacional de la Patagonia San Juan Bosco (U.N.P.S.J.B.) - Facultad de Ciencias Económicas (F.C.E)

CANTAMUTTO, F. (2016). El tarifazo: breve estudio sobre el caso del gas, Documento $\mathrm{N}^{\mathrm{o}}$ 15, Fundación Friedrich Ebert Argentina.

CYNUEL, V. (2019). Trabajo y estructura productiva en el sector de extracción de hidrocarburos. Las provincias de Neuquén, Chubut y Santa Cruz (2006-2015). X Jornadas de Sociología "Escenarios recientes en América Latina: democracia, derechos y derechas" Área de Sociología - Instituto de Ciencias - UNGS.

DAICZ, L., MONLEZÚN, G. (2016). El derrumbe del precio del petróleo y sus consecuencias para América Latina. Dirección Nacional. Centro de Economía Internacional. Ministerio de Relaciones Exteriores y Culto.

FIGARI, C., y PALERMO, H. M. (2009). Prácticas hegemónicas empresariales, dispositivos de control laboral y valorización de la experiencia. Theomai, (19), 59-75.

FRANZOSI, R. (2017). La prensa como fuente de datos socio-históricos: Cuestiones sobre la metodología de recolección de datos a partir de periódicos. Revista de estudios Marítimos y Sociales, 1(11), 255-286

KOZINER, N., y ZUNINO, E. (2013). La cobertura mediática de la estatización de YPF en la prensa argentina: un análisis comparativo entre los principales diarios del país. Global Media Journal, 10(19), 1-25.

KULFAS, M. (2019). Los tres kirchnerismos: una historia de la economía argentina, 20032015. Siglo XXI Editores.

LANDRISCINI, G. (2015). Reorganización productiva e innovación a partir de los hidrocarburos de reservorios no convencionales en la Cuenca Neuquina. Alianzas, redes, subcontratación y tercerización. 12 Congreso Nacional de Estudios del Trabajo. El trabajo en su laberinto.Viejos y nuevos desafíos. Buenos Aires, 5, 6 y 7 de Agosto.

LANDRISCINI, G. (2017). Cambios en las relaciones del trabajo en la Cuenca Hidrocarburífera Neuquina. Desregulación, reestructuración y flexibilidad en los reservorios no convencionales. 13 Congreso Nacional de Estudios del Trabajo. El trabajo en conflicto. Dinámicas y expresiones en el contexto actual. Buenos Aires, 2,3 y 4 de Agosto.

LANDRISCINI, G. (2018). Reorganización sectorial y flexibilidad laboral en la Cuenca Hidrocarburífera Neuquina. XXVI Jornadas de Historia Económica. Facultad de Ciecnias Humanas. Universidad Nacional de La Pampa. Santa Roza, La Pampa, 19, 20 y 21 de Septiembre.

LANDRISCINI, G. (2019). Subcontratación y flexibilidad laboral en los reservorios no convencionales de hidrocarburos en Vaca Muerta. Los riesgos del trabajo y los conflictos en la Cuenca Neuquina. 14 Congreso Nacional de Estudios del Trabajo. Los trabajadores y las trabajadores en el escenario actual. Condiciones estructurales y alternativas frente a la crisis. Buenos Aires, 7,8 y 9 de Agosto

MANSILLA, D. (2007). Hidrocarburos y política energética. De la importancia estratégica al valor económico: Desregulación y Privatización de los hidrocarburos en Argentina. Buenos Aires: Ediciones del CCC.

MARÍN, J. C. (2007). El ocaso de una ilusión: Chile 1967/1973. Buenos Aires: Ediciones PICASO.

MINISTERIO DE HACIENDA DE LA NACIÓN (2016). Informe de cadenas de valor: Hidrocarburos. Buenos Aires: Ministerio de Hacienda de la Nación.

MINISTERIO DE HACIENDA DE LA NACIÓN (2017). Informes productivos provinciales: Chubut N2 (16) Buenos Aires: Ministerio de Hacienda de la Nación 
MINISTERIO DE HACIENDA DE LA NACIÓN (2018a). Informe de cadenas de valor: Hidrocarburos. Buenos Aires: Ministerio de Hacienda de la Nación.

MINISTERIO DE HACIENDA DE LA NACIÓN (2018b). Informes productivos provinciales: Santa Cruz. N3 (18). Buenos Aires: Ministerio de Hacienda de la Nación

MUÑIZ TERRA, L. (2008). Los eslabones invisibles de la reestructuración productiva: las empresas subcontratistas de Repsol YPF y sus trabajadores. Trabajo y sociedad: Indagaciones sobre el empleo, la cultura y las prácticas políticas en sociedades segmentadas, (10), 3.

MUÑIZ TERRA, L. (2012). Los (ex) trabajadores de YPF: trayectorias laborales a 20 años de la privatización. Espacio Editorial.

ORLANSKY, D. y MAKÓN, A. (2003). De la sindicalización a la informalidad. El caso de Repsol YPF. Revista argentina de sociología, 1(1), 7-26.

PALERMO, H. M. (2012). Cadenas de oro negro en el esplendor y ocaso de YPF. Grupo Antropología del Trabajo.

PALERMO, H. M. (2013). Apuntes para pensar la nacionalización de YPF: relaciones laborales y tensiones sociales en Comodoro Rivadavia. CLACSO.

PÉREZ, V. (2015). Las vías de la transición. Transformaciones emergentes en el modelo de prestación de los servicios ferroviarios de pasajeros del área metropolitana de Buenos Aires (1990-2010). Documentos de Trabajo. Serie estudios del Transporte. Instituto del Transporte. Universidad Nacional de San Martín; Lugar: Buenos Aires: vol. 1 p. 1 $-47$.

PÉREZ ROIG, D. (2018). Políticas de promoción de 'formas extremas' de energía en la Argentina postconvertibilidad (2002-2015). Tesis Doctoral. Facultad de Ciencias Sociales. Universidad de Buenos Aires.

PORTA, F., SANTARCÁNGELO, J., y SCHTEINGART, D. (2017). Un proyecto político con objetivos económicos. Los límites de la estrategia kirchnerista. Los años del kirchnerismo. La disputa hegemónica tras la crisis del orden neoliberal, 99-143. Siglo XXI

PRADO, M. y ROBLEDO, M. (2015a). La actividad petrolera en la zona norte de la provincia de Santa Cruz: el papel de los actores empresariales regionales y su relación con el desarrollo territorial. Revista de estudios regionales y mercado de trabajo, 11, 101-120.

PRADO, M. y ROBLEDO, M. (2015a) Análisis y evolución de la actividad hidrocarburífera en la zona norte de la provincia de Santa Cruz y su impacto en el desarrollo local. Período 2000-2013 Informes Científicos y Técnicos. $113 . \quad 70-89$ http://dx.doi.org/10.22305/ict-unpa.v7i2.128

RÍO, A. (2008). Usos y abusos de la prensa como fuente de datos sobre acciones colectivas. EMPIRIA. Revista de Metodología de Ciencias Sociales. Número 16. 59-84.

SABBATELlA, I. (2012). La Política Petrolera de la Posconvertibilidad: De la Herencia Neoliberal a la Expropiación de YPF. Argumentos. Revista de Crítica Social. Número 12.

SALVIA, A. (1999). La Patagonia de los noventa: Sectores que ganan, Sociedades que pierden. Buenos Aires: La Colmena.

SANTARCÁNGELO J., y PADÍN, J. (2019). La reinstauración del neoliberalismo en Argentina durante el gobierno de la Alianza Cambiemos (2015-2019). Realidad Económica. IADE. CABA. 33-57. 
SCHINELLI, D. A., VACCA, C. A., LURBÉ, R. M., WILliAMS, M. M., AGUllA, A., OYARZO, L., ANTOLA, A. R, LÓPEZ, G. y SANCHEZ, A. S. (2019). Dinámica productiva en santa cruz. Su transformación e incidencia en el empleo. En Arpes, M. (comp.) Encuentro en el extremo. 1a ed. - Río Gallegos: Universidad Nacional de la Patagonia Austral, 17.

SCHUSTER, F., PÉREZ, G., PEREYRA, S., ARMESTO, M., ARMELINO, M., GARCÍA, A., NATALUCCI, A., VAZQUEZ, M. y ZIPCIOGLU, P. (2006). Transformaciones de la protesta social en Argentina 1989-2003. Documentos de trabajo, 48(1), 1-70.

SERRANI, E. (2013). Transformaciones recientes en la industria petrolera argentina: el caso de Yacimientos Petrolíferos Fiscales, 1989-2012. Revista de Gestión Pública, 2(1), 247-280.

SERRANI, E., BARRERA, M., SABBATELlA, I. y ORTIZ, M. (2017). Cambios y continuidades en la orientación de la política energética del primer año de la alianza. Cambiemos X Jornadas de Economía Crítica. Buenos Aires.

SILVER, B. (2005). Fuerzas del trabajo. Los movimientos obreros y la globalización desde 1880. Madrid: Akal.

SVAMPA, M. (2002). Movimientos sociales en la Argentina de Hoy. Piquetes y Asambleas. CEDES.

TARROW, S. (1999). El poder en movimiento. Los movimientos sociales, la acción colectiva y la política. Madrid: Alianza Editorial.

TARROW, S. (2008). Charles Tilly and the Practice of Contentious Politics. Social Movement Studies, 7 (3), 225-246.

TILLY, C. (2000). Acción colectiva. Apuntes de Investigación del CECyP, 6, 9-32.

TILLY, C. (2008). Contentious performances. NY: Cambridge University Press.

VEGA, A., RUIZ, S., AVILA, S., MURUA, M., ARCE, A. y VÁZQUEZ, A. (2012). Tensiones en clúster de servicios petroleros del Golfo San Jorge: Avances en la caracterización de conflictos. XI INTI International Conference. La Plata, 17 al 20 de octubre 2012, La Plata, Argentina.

VILLARROEL, M. N., SCHINELLI, D., VACCA, C. (2018). La evolución de la producción y de la inversión en el sector petrolero y gasífero en Argentina. Informes Científicos y Técnicos 185 1-9 http://dx.doi.org/10.22305/ict-unpa.v10i3.283

WRIGHT, E. O. (2010). Preguntas a la desigualdad. Ensayos sobre el análisis de clase, socialismo y marxismo, Bogotá, Editorial Universidad del Rosario.

WRIGHT, E. O. (2013). Envisioning real utopias, New York, Verso.

\section{Informes y documentos de la empresa}

YPF (2013) Comunicación de Progreso 2013. Recuperado de: https://www.ypf.com/LaCompania/Documents/YPF-COP-2013.pdf

YPF (2014). Comunicación de Progreso 2014. Recuperado de: https://www.ypf.com/LaCompania/Documents/Comunicacion-de-progreso-2014.pdf

YPF (2015). Comunicación de Progreso 2015. Recuperado de: https://s3-us-west2.amazonaws.com/ungcproduction/attachments/cop_2016/312211/original/YPF_COP 2015.pdf?1472594406

YPF (2016). Reporte de Sustentabilidad 2016. Recuperado de: https://www.ypf.com/LaCompania/Documents/YPF-Reporte-Sustentabilidad-2016.pdf YPF (2017). Reporte de Sustentabilidad 2017. Recuperado de:

https://www.ypf.com/LaCompania/Documents/YPF-Reporte-de-Sustentabilidad-2017.pdf 
YPF (2018). Reporte de Sustentabilidad 2018. Recuperado de: https://www.ypf.com/LaCompania/Documents/YPF-Reporte-de-Sustentabilidad2018.pdf

\section{Notas Periodísticas}

Adhesión total a la medida (23 de noviembre de 2012). Diario Río Negro. Recuperado de: https://www.rionegro.com.ar/adhesion-total-a-la-medida-MQRN_1013851/

Arias, M. (2011a) "Sigue el paro petrolero en Santa Cruz" La Nación. Recuperado de: https://www.lanacion.com.ar/economia/sigue-el-paro-petrolero-en-santa-cruznid 1363460

Arias, M. (2011b) "Petroleros acaban de tomar una planta en Las Heras" La Nación https://www.lanacion.com.ar/economia/petroleros-acaban-de-tomar-una-planta-en-lasheras-nid1379899

Alto porcentual de petroleros en las urnas (20 de noviembre de 2013). Tiempo Sur. Recuperado de: https://www.tiemposur.com.ar/nota/61918-alto-porcentual-depetroleros-en-las-urnas

Buscan frenar despidos en el sector petrolero neuquino (21 de mayo de 2015). Diario Río Negro. Recuperado de: https://www.rionegro.com.ar/region/buscan-frenar-despidosen-el-sector-petrolero-neuquino-FPRN_7592491

Dos mil petroleros respaldaron el reclamo de 45\% de aumento (13 de noviembre de 2004) Diario Río Negro. Recuperado de: https://www.rionegro.com.ar/dos-mil-petrolerosrespaldaron-el-reclamo-de-45-de-aumento-JBHRN04111319131020/

Claudio Vidal ganó las elecciones y conducirá el gremio por cuatro años más /22 de septiembre de 2017) Tiempo Sur. Recuperado de: https://www.tiemposur.com.ar/nota/139350-claudio-vidal-gano-las-elecciones-yconducira-el-gremio-por-cuatro-anos-mas

El crudo no detiene su carrera y el gobierno analiza subir las retenciones (31 de julio de 2004). Diario Río Negro. Recuperado de: https://www.rionegro.com.ar/argentina/elcrudo-no-detiene-su-carrera-y-el-gobierno-analiza-subir-las-retencionesAAHRN0407311431701

El 30\% de los equipos de perforación está parado (19 de diciembre de 2015). Diario Río Negro. Recuperado de: https://www.rionegro.com.ar/energia/el-30-de-los-equipos-deperforacion-esta-parado-LARN_8026786

Hay más bloqueos y se teme que falta nafta (2011) La Nación Recuperado de: https://www.lanacion.com.ar/economia/hay-mas-bloqueos-y-se-teme-que-falte-naftanid1373943

Intervención de Petroleros Privados inició su trabajo (26 de octubre de 2011) Tiempo Sur. Recuperado de: https://www.tiemposur.com.ar/nota/30950-intervencion-de-petrolerosprivados-inicio-su-trabajo

La cámara petrolera planteó la crítica situación del sector (27 de febrero de 2009) Recuperado de: $\quad$ https://www.rionegro.com.ar/region/la-camara-petrolera-planteo-la-criticasituacion-del-sector-BDHRN1235622884216

Neuquén convoca a YPF por la crisis petrolera (15 de febrero de 2009). Diario Río Negro. Recuperado de: https://www.rionegro.com.ar/region/neuquen-convoca-a-ypf-por-lacrisis-petrolera-MCHRN1234670145218

Reclaman un aumento del 52\% a Repsol (28 de septiembre de 2004). Diario Río Negro. Recuperado de: https://www.rionegro.com.ar/region/reclaman-un-aumento-del-52-arepsol-OHHRN0409281928756 
Riesco advirtió sobre un estallido (27 de marzo de 2009) Diario Río Negro. Recuperado de: https://www.rionegro.com.ar/region/rioseco-advirtio-sobre-un-estallido

Un paro de petroleros podría generar desabastecimiento (7 de octubre de 2005). La Nación. Recuperado de: https://www.lanacion.com.ar/economia/un-paro-de-petroleros-podriagenerar-desabastecimiento-nid747385

Vidal manifestó que "YPF debe tener una mirada más amplia" (21 de noviembre de 2016). Tiempo Sur. Recuperado de: https://www.tiemposur.com.ar/nota/120918-vidalmanifesto-que-ypf-debe tener-una-mirada-mas-amplia

YPF achica inversiones y afecta al empleo (5 de marzo de 2016). Diario Río Negro. Recuperado de: https://www.rionegro.com.ar/portada/ypf-achica-inversiones-y-afectaal-empleo-NARN_8089608

YPF bajará 33 equipos petroleros que estaban inactivos en Neuquén (1 de noviembre de 2016). Diario Río Negro. Recuperado de: https://www.rionegro.com.ar/region/ypfbajara-33-equipos-petroleros-que-estaban-inactivos-en-neuquen-XC1721213 